\title{
Correction to: The Hauntology of Everyday Life
}

\section{Correction to:}

\section{S. Rahimi, The Hauntology of Everyday Life,} https://doi.org/10.1007/978-3-030-78992-3

The book was inadvertently published with the incorrect affiliation as "Massachusetts Institute of Technology, Cambridge, MA, USA" in the copyright page, whereas it should be "Harvard Medical School, Boston, MA, USA". This has been updated in the book.

The updated version of the book can be found at https://doi.org/10.1007/978-3-030-78992-3

(C) The Author(s), under exclusive license to Springer Nature Switzerland AG 2021

S. Rahimi, The Hauntology of Everyday Life, https://doi.org/10.1007/978-3-030-78992-3_7 